\title{
The effectiveness of peer education interventions on HIV- and HBV-preventive behaviours in women with substance-related disorders: a cluster randomised control trial
}

\author{
Soheila Ahmadi ${ }^{1}$, Mansoureh Jamshidimanesh², Mohammad Bagher Saberi Zafarghandi ${ }^{3}$, Hadi Ranjbar ${ }^{3}$ \\ ${ }^{1}$ Iran University of Medical Sciences, Tehran, Iran \\ ${ }^{2}$ Department of Midwifery, School of Nursing and Midwifery, Iran University of Medical Sciences, Tehran, Iran \\ ${ }^{3}$ Department of Addiction, School of Behavioural Sciences and Mental Health, Tehran Institute of Psychiatry, Iran University of Medical
} Sciences, Tehran, Iran

\begin{abstract}
Introduction: Substance-related disorders (SRDs) have become a problematic phenomenon in many countries, including Iran. Risky sexual behaviours are highly prevalent among people with SRDs. This study aimed to evaluate the effectiveness of a peer education program on preventive behaviours related to human immunodeficiency virus (HIV) and hepatitis B virus (HBV) in women with SRDs.

Material and methods: One hundred eligible female drug abusers from 10 drop-in centres located in Tehran were entered into the study using convenience sampling. The intervention included six training sessions. Sessions were held in small groups and conducted by peer educators. The primary topics discussed were problem-solving skills, and HIV/HBV disease-related information including testing, transmission, and prevention. All participants completed demographic and sexual function questionnaires prior to, one-, and three-months post-intervention.

Results: The results showed a significant decrease in the percentage of drug $(96.00 \%, 75.55 \%, 73.52 \%$, $p=0.001)$ and alcohol use $(32.00 \%, 13.33 \%, 2.90 \%, p=0.000)$ prior to sexual intercourse in the intervention group. Additionally, the number of sex acts under the influence of drugs and alcohol decreased significantly $(p<0.001)$. The number of sexual partners $(p<0.000)$ significantly declined, but total drug use indicated no change. We found increases in the percentage of women who reported having had a recent HIV test $(p<0.001)$ and in condom use $(p<0.001)$, but the control group showed no significant difference.

Conclusions: Based on current results, peer education programs can have a positive effect on high-risk sexual behaviours related to HIV and HBV in women with substance-related disorders. The potential influence of peers in health interventions should be given greater consideration.
\end{abstract}

HIV AIDS Rev 2019; 18, 3: 183-192 DOI: https://doi.org/10.5114/hivar.2019.88475

Key words: condom use, educational programmes, knowledge, high school students, prevention.

Address for correspondence: Mansoureh Jamshidimanesh, $\mathrm{PhD}$, School of Nursing \& Midwifery, Rashid Yasemi St., Valiasr St., Tehran, Iran, phone: +98-43651000, fax: +98-88201978, e-mail: jamshidimanesh.m@iums.ac.ir
Article history:

Received: 07.07.2018

Received in revised form: 15.02.2019

Accepted: 07.03.2019

Available online: 06.09.2019
International Journal of HIV-Related Problems

HIV \& AIDS

R e v i e w 


\section{Introduction}

Substance-related disorders (SRDs) have become one of the most serious social and health system issues in recent years [1]. There is no reliable estimation of substance-related disorders in Iran, but according to the last prevalence study, the number of drug users was estimated at $1,325,000$, which accounted for $2.65 \%$ of the population over 15 years old. According to the Ministry of Health of Iran, the ratio of women to men with SRDs is one to eight [2]. Currently, Iranian studies indicate that in Iran $9.6 \%$ of the drug-dependent people are women, representing an increased tendency to substance abuse in Iran [3].

Substance abuse plays a major role in human immunodeficiency virus (HIV) infection transmission; approximately $29 \%$ of HIV-infected women contracted the virus through injecting drugs, and another $15 \%$ contracted it through sexual contact with an HIV-infected drug user. In 2017, an estimated $47 \%$ of new infections occurred among key populations and their partners $[4,5]$. Despite significant advances in the prevention of HIV/acquired immunodeficiency syndrome (AIDS) and hepatitis, injection drug use continues to contribute to new infections, both directly through the sharing of injection equipment, and indirectly through sexual transmission from injection drug use (IDU) to non-IDU sex partners [6-9]. The exchange of sex for drugs or money, another risk factor for HIV infection, is common among those who abuse drugs [5]. Risky sexual behaviours (RSBs) are highly prevalent among people with SRDs because being under the influence of a substance can disrupt the judgment of the individual, resulting in involvement in risky behaviours, particularly RSBs [10-12], and it often leads to adverse health outcomes [13] such as reduced or no condom use, an increased number of sexual partners - particularly when combined with illicit drugs and alcohol use - and sex with high-risk sexual partners, as well as exchanging sex for drugs or money, resulting in an increased risk of HIV and hepatitis $B$ virus (HBV) infection [5, 10, 12-14].

Health systems have a history of using peers to achieve the aims of preventing the onset of disease, thereby reducing the severity or duration, or adverse consequences associated with disease [15]. The peer group function is defined as the facilitation of behavioural change through the provisioning of information, training, and/or peer-to-peer support services [16]. Peers are familiar with the risks and concerns of local people and can help those who do not have healthcare facilities to establish such services. Peer group programs aim to empower both the instructor group and target group by enhancing solidarity and collective activity [17]. These programs mainly focus on information pertaining to reducing damage, prevention, and early intervention [18]. Furthermore, as an essential component, these programs have also been defined as preventing HIV by using peers as educational resources, changing practice, and delivering care $[19,20]$. Although peer education has been implemented successfully among drug-abusing populations in a variety of settings, this approach was usually utilised among indi- viduals already seeking treatment or other services, rather than among street-based drug users who have not initiated service contact, as represented by our sample [21].

Women are more vulnerable to being exposed to HIV and HBV infection [22]; the reasons for this include being biologically susceptible, working as sex workers, and being victims of rape. Additionally, women may not be able to ask or convince their partner to wear a condom [23, 24]. This is particularly the case for women with substance-use disorders [25]. Failure to identify infected individuals, particularly those engaging in risky sexual behaviour, can lead to the spread of disease in society and irrevocable complications. According to the World Health Organisation, women with SRDs should be a special target in the prevention and treatment programs, because they use health services much less than men with SRDs [26]. In the present study, we explore the effect of peer education on the risk behaviours of women with SRDs.

\section{Material and methods}

This cluster randomised controlled study was conducted in 10 drop-in centres in Tehran, the capital of Iran, between March and October 2017. The centres were randomly assigned into two groups by random allocation: control and intervention, by a research assistant who had no knowledge of the centres. The research assistant also performed the sample size calculation. In Tehran, there are approximately 25 centres in which there is a possibility of research, but we only obtained permission for 10 of them, so allocation was conducted in the centres via cluster randomisation into five intervention and five control groups. This method was chosen because drug-using women were in close relationship with one another, and there was the possibility of information contamination. The target population was entered into the study using convenience sampling. All eligible women in both centres (control and intervention), who had the inclusion criteria and consent to enrol in research, were asked to participate in the study. Inclusion criteria were: being female; 18 years of age or older; being conscious to respond to conversations at the time of participating in the class, and able to completing the questionnaire; having the ability to read and write in Persian; being sexually active; and having an absence of HIV and HBV (based on self-report or recorded in their personal care notes). Exclusion criteria were: reporting a positive diagnosis of current HIV and HBV and being absent from the class for more than one session. Signed consent was obtained for all participants included site managers, individual participants, and peer educators.

\section{Peer educator training [27]}

The goals of the peer educator training (PET) program were: (1) to increase knowledge of HIV and HBV; (2) to develop presentation skills; and (3) to implement the intervention. At first, two volunteer persons who had quit using drugs were selected from each intervention centre as peer educators. The eligibility criteria were being female, aged 18 to 40 years, 
having a history of using drugs, having reading and writing skills in Persian, and being sexually active. Candidates had to demonstrate the basic social and presentation skills necessary to become a peer educator. Also, they were made familiar with the assessment skills, the concept of peer education, and educational needs. They received a training course totalling 30 hours, which was conducted by the first author. The course material included information about interpersonal skills, counselling skills, interviewing techniques, HIV and HBV definitions, HIV and HBV transmission methods, sexually transmitted infections, HIV and HBV prevention techniques, and discourse skills for negotiating with a sexual partner. Group activities included games, role-playing, storytelling, and condom demonstrations.

\section{Peer education [18]}

Peer education (PE) delivered to the intervention group consisted of six sessions, each of which lasted approximately one hour. The time was dependent on the proposed subjects and the type of provided services within each session. Sessions were held in group form, and in each session the peer educator trained between eight and 10 women with a substance-use disorder, who had been referred to one of the centres [28]. The control group received 'usual care', which included access to all of the basic services (e.g. food, hygiene), case management, and programs that were available at the drop-in centre at the time of the study. We maintained contact with participants in the control group by giving them some gifts and filling the questionnaire before, and one and three months after intervention. The peer educators followed a structured education plan with supervision from the corresponding author. In the first session, researchers explained the method and purpose of the study to all eligible women who wished to participate, collected written consent, and completed the questionnaire within 30 minutes. After a short break, the peer educator provided information regarding genital anatomy and physiology. The second session: at the beginning of the session, the previous session was reviewed in 15 minutes, then the transmission and prevention methods of HIV and HBV were explained. The third session: topics included the identification of high-risk situations and safe-sex behaviours; the use of a male and a female condom on penis and vaginal models were shown to participants, and they were given the opportunity to practice these once. The fourth session: this session included discourse, negotiation, and problem-solving skills. This session was designed to increase participants' self-efficacy perceptions. The fifth and sixth sessions: these included questions and answers about the topics of the previous sessions at the start of the session, role-playing, telling stories, and effecting scenarios.

Participants received a personalised feedback form at the start of each session, which was populated with their responses to certain baseline survey questions, relevant to that session's content. This personalised feedback was intended to: (1) strengthen engagement in the program by increasing its personal relevance; (2) help youths assess their cur- rent situation and identify potential changes they can make to be safer in the future if they were interested in doing so; (3) maximise the time devoted to curriculum delivery by collecting important information for group discussions ahead of time; and (4) provide participants with additional information, such as online resources and skills training tips for making healthier choices. One and three months after the sessions, the questionnaire was distributed among participants, and their performance in the prevention of HIV and HBV was assessed.

At the end of each session, the participants were given the opportunity to ask questions and discuss the given information as a group or individually. The techniques applied in the sessions were slide shows, lectures, question-and-answer sessions, brainstorming, role-playing, and training videos. A pamphlet consisting of six pages of summary information about HIV and HBV was given to participants after the intervention so they could review the session material.

\section{Measures}

The data-gathering tool consisted of three parts: a demographic characteristics questionnaire, history of substance use, and sexual behaviours; it was created by Jamshidimanesh [29], who reported its reliability and validity ( $\alpha=0.87$ ). The demographic section comprised 12 items (age, education, marital status, number of casual partners, having permanent partners, marriage age, previous residence, number of children, place of accommodation, occupation, knowing someone who is HIV positive, and their relationship with someone who is HIV positive). The questions in the second part (13-24) related to substance use information including drug type, drug history, drug use interval, years of drug use, alcohol use, injection history, and partner's drug history. In the third part (25-59) information about sexual behaviours and performance was assessed. The questions in the third part included: age at first sexual intercourse, having anal intercourse, having oral intercourse, having vaginal intercourse, number of sexual partners, drug use before sexual intercourse, alcohol use before sexual intercourse, condom use, and status of HIV and HBV tests (Figure 1).

\section{Statistical analysis}

SPSS (version 24) was used to analyse the data. The differences between the demographics of the intervention and control groups were assessed using chi-square tests because this was categorical data. Independent $t$-tests and paired $t$-tests were used to compare the differences between the baseline and endof-follow-up scores within the groups and between each group. A repeated measures ANOVA was used to compare the preand post-intervention scores within and between groups.

\section{Ethical consideration}

Ethical approval and permission were given by Iran University of Medical Sciences, Tehran, Iran, and the State Wel- 


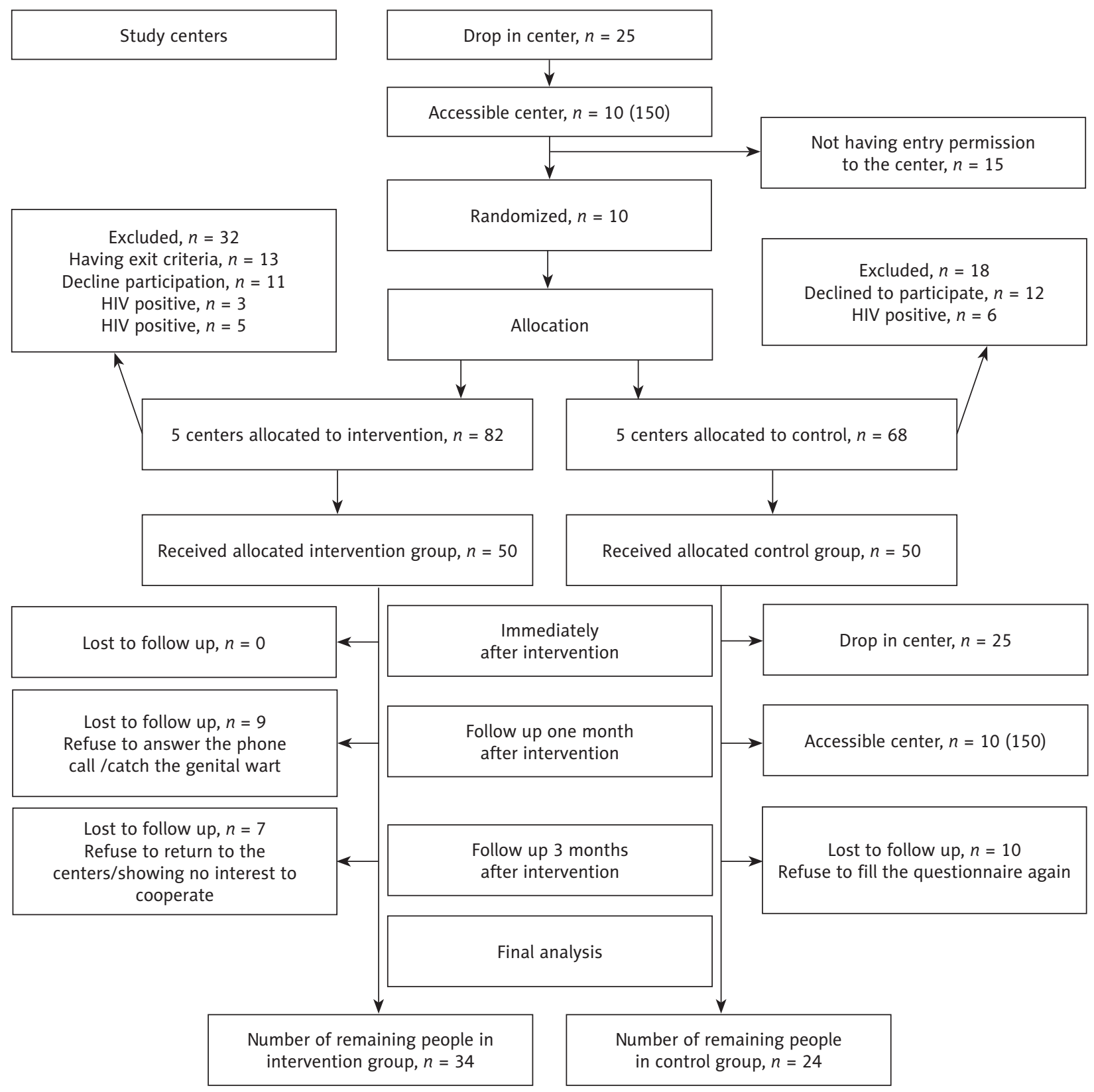

Figure 1. Flowchart of the participant's progress through the phases of trial

fare Organisation of Iran (IR.IUMS.REC.1395.9311373001). The trial was also registered in the Iranian trial registry system (IRCT201612113034N17). All participants signed an informed consent form and were assured that their information would remain confidential.

\section{Results}

\section{General characteristics of the participants}

One hundred women with SRDs were enrolled in this randomised-controlled trial. The number of participants at one-month follow-up were 45 and 39 in the intervention and control groups, respectively. At the three-month follow-up, 34 women in the intervention group and 24 in the control group completed the study questionnaires (Figure 1).

The mean age of the participants involved in the study was $28.57 \pm 6.56$ years. The majority had some formal education and were single and unemployed. The participants' mean age at first sexual intercourse was $16.39 \pm 3.077$ years. The most common sexual activity in both intervention and control groups was vaginal intercourse. The results showed that more than half of the participants in both the inter- 
vention and control group had three or more sexual partners. Findings indicate that more than half of the participants had sexual partners with a prison history. Only $20.8 \%$ of the intervention group and $20 \%$ of the control group used the condom during sexual intercourse. Most of the study participants reported the main reason for not using a condom to be their own and their partner's unwillingness to do so. The primary characteristics were similar in both groups (Table 1).

In this study, methamphetamine was the most used substance in both the intervention and control groups. Eight per cent of intervention group participants and $12 \%$ in the control group had a history of injection. The women in both the intervention (46\%) and control (48\%) groups always used substances prior to sexual activity, and $32 \%$ of the intervention group, as well as $34 \%$ of the control group, sometimes used substances prior to sexual activity. Alcohol use prior to sexual activity in the intervention group was $32 \%$, and $38 \%$ in the control group. Moreover, the independent $\mathrm{t}$-test showed that these two groups rated similarly in terms of daily use and consumption years $(p>0.05)$. Prior to the intervention, the two groups were similar in terms of measured variables and showed no significant statistical difference $(p>0.05)$.

\section{The effect of peer education program on sexual risk behaviour, and HIV and HBV prevention}

The percentage of drug $(96 \%, 75.55 \%, 73.52 \%$, $p=0.001)$ and alcohol use $(32 \%, 13.33 \%, 2.9 \%, p=0.000)$ before sexual intercourse declined significantly in the intervention arm, but in the control arm there was no significant difference $(98 \%, 94.87 \%, 100 \%, p=0.368$ ) (Table 2). Also, the number of sex acts performed under the influence of drugs and alcohol decrease significantly in the intervention group $(p=0.000)$ while it was unchanged in the control group. The mean number of sexual partners before the intervention was $3.866 \pm 2.767$ and $3.35 \pm$ 2.443 in the intervention and control group, respectively. The intervention was effective in reducing the number of sexual partners at one- and three-month follow-ups in the intervention group $(p=0.000)$. The mean number of sexual partners in the control group showed a slight reduction that was not significant. The intervention group showed a significant increase in condom use in the last and last 10 sexual intercourses $(p=0.000)$. In the control group, no significant difference was seen in the follow-ups. The prevalence of HIV and HBV testing was $(40 \%, 64.2 \%, 45.8 \%, p=1.000)$ and $(38 \%, 60 \%, 82.8 \%$, $p=0.000)$ in the control and intervention groups, respectively. HIV and HBV testing improved significantly in the intervention arm. In the control group at one-month follow-up the testing rate was improved. The HIV and HBV testing rates were slightly higher in the intervention group (Table 3 ).
Table 1. General characteristics of the intervention and control groups $(N=100)$

\begin{tabular}{l|c|c|c}
\hline Variable & $\begin{array}{c}\text { Intervention } \\
n=50(\%)\end{array}$ & $\begin{array}{c}\text { Control } \\
n=50(\%)\end{array}$ & $\begin{array}{c}\text { Statistical } \\
\text { analysis } \\
p \text { value }\end{array}$ \\
\hline
\end{tabular}

\begin{tabular}{|c|c|c|c|}
\hline \multicolumn{4}{|c|}{ Age group (in years) } \\
\hline Less than 20 & $6(12)$ & $3(6)$ & \multirow{4}{*}{$p=0.643^{*}$} \\
\hline $20-29$ & $22(44)$ & $22(44)$ & \\
\hline $30-39$ & $20(40)$ & $24(48)$ & \\
\hline More than 40 & $2(4)$ & $1(2)$ & \\
\hline \multicolumn{4}{|l|}{ Education } \\
\hline Primary & $3(6)$ & $4(8)$ & \multirow{4}{*}{$p=0.925^{\star}$} \\
\hline Middle school & $18(36)$ & $16(32)$ & \\
\hline High school & $24(48)$ & $26(52)$ & \\
\hline Academic & $5(10)$ & $4(8)$ & \\
\hline
\end{tabular}

Job

\begin{tabular}{|c|c|c|c|}
\hline Unemployed & $39(78)$ & $35(70)$ & \multirow{4}{*}{$p=0.756^{*}$} \\
\hline Employee & $4(8)$ & $4(8)$ & \\
\hline $\begin{array}{l}\text { Manual } \\
\text { worker }\end{array}$ & $4(8)$ & $5(10)$ & \\
\hline Free job & $3(6)$ & $6(12)$ & \\
\hline \multicolumn{4}{|c|}{ Marital status } \\
\hline Married & $17(34)$ & $18(36)$ & \multirow{4}{*}{$\begin{aligned} p & =0.692 \\
X^{2} & =1.452^{\star *} \\
d f & =3\end{aligned}$} \\
\hline Single & $14(28)$ & $17(34)$ & \\
\hline Widow & $3(6)$ & $1(2)$ & \\
\hline Divorced & $16(32)$ & $14(28)$ & \\
\hline
\end{tabular}

\begin{tabular}{|c|c|c|c|}
\hline \multicolumn{4}{|l|}{ Age at first sex } \\
\hline Less than 15 & $19(38)$ & $21(42)$ & \multirow{3}{*}{$p=0.569^{\star}$} \\
\hline $16-25$ & $29(58)$ & $29(58)$ & \\
\hline More than 26 & $2(4)$ & $0(0)$ & \\
\hline
\end{tabular}

\begin{tabular}{|c|c|c|c|}
\hline \multicolumn{4}{|c|}{ Sexual partner } \\
\hline Yes & 47 (94) & $46(92)$ & \multirow{2}{*}{$p=1^{*}$} \\
\hline No & $3(6)$ & $4(8)$ & \\
\hline
\end{tabular}

\begin{tabular}{|c|c|c|c|}
\hline \multicolumn{4}{|l|}{ Sexual type } \\
\hline Vaginal & $42(84)$ & 45 (90) & $p=0 / 372$ \\
\hline Anal & $41(82)$ & $27(54)$ & $p=0.003$ \\
\hline Oral & $41(82)$ & $36(72)$ & $p=0.235$ \\
\hline $\begin{array}{l}\text { Vaginal, anal, } \\
\text { oral }\end{array}$ & $29(58)$ & $22(44)$ & $p=0.161$ \\
\hline
\end{tabular}

\begin{tabular}{|c|c|c|c|}
\hline \multicolumn{4}{|l|}{ Multiple partner } \\
\hline 1 partner & $10(20)$ & $9(18)$ & \multirow{3}{*}{$\begin{array}{c}p=0.824 \\
X^{2}=0.387 \\
d f=2\end{array}$} \\
\hline 2 partners & $12(24)$ & $10(20)$ & \\
\hline 3 or more & $28(56)$ & $31(62)$ & \\
\hline \multicolumn{4}{|l|}{ Condom use } \\
\hline Yes & $5(10)$ & $8(16)$ & \multirow{3}{*}{$\begin{array}{c}p=0.611 \\
X^{2}=0.986 \\
d f=2\end{array}$} \\
\hline No & $34(68)$ & $30(60)$ & \\
\hline Sometimes & $11(22)$ & $12(24)$ & \\
\hline
\end{tabular}


Table 1. Cont.

\begin{tabular}{|c|c|c|c|}
\hline Variable & $\begin{array}{c}\text { Intervention } \\
n=50 \text { (\%) }\end{array}$ & $\begin{array}{c}\text { Control } \\
n=50(\%)\end{array}$ & $\begin{array}{c}\text { Statistical } \\
\text { analysis } \\
p \text { value }\end{array}$ \\
\hline \multicolumn{4}{|c|}{ Drug use before sex } \\
\hline Yes & $23(46)$ & $9(18)$ & \multirow{3}{*}{$\begin{array}{c}p=0.882 \\
X^{2}=0.252 \\
d f=2\end{array}$} \\
\hline No & $11(22)$ & $24(48)$ & \\
\hline Sometimes & $16(32)$ & $17(34)$ & \\
\hline \multicolumn{4}{|c|}{ Alcohol use before sex } \\
\hline Yes & $16(32)$ & $19(38)$ & \multirow{2}{*}{$\begin{array}{c}p=0.52 \\
X^{2}=0.396 \\
d f=1\end{array}$} \\
\hline No & $34(68)$ & $31(62)$ & \\
\hline \multicolumn{4}{|l|}{ Drug type } \\
\hline $\begin{array}{l}\text { Give up less } \\
\text { than } \\
3 \text { months }\end{array}$ & $9(18)$ & $8(16)$ & \multirow{6}{*}{$\begin{array}{c}p=0.829 \\
X^{2}=2.144 \\
d f=5\end{array}$} \\
\hline Crystal & $14(28)$ & $10(20)$ & \\
\hline Heroin & $4(8)$ & $7(14)$ & \\
\hline Opium & $3(6)$ & $5(10)$ & \\
\hline $\begin{array}{l}\text { Crystal and } \\
\text { heroin }\end{array}$ & $9(18)$ & $10(20)$ & \\
\hline Multi drug & $11(22)$ & $10(20)$ & \\
\hline
\end{tabular}

\section{Discussion}

The findings from this study show that young women with SRDs are at high-risk of getting and transmitting HIV and HBV, as demonstrated by their reported sexual risk behaviours. The results showed that the peer's intervention led to the reduction of high-risk sexual behaviours in women with SRDs. Condom use, as an outcome in the last sexual intercourse, especially with sex partner who has a prison history, and frequency of condom use in 10 sexual intercourse episodes showed a significant increase one and three months after the intervention. While the control group did not show significant change (Tables 2 and 3 ). These results show that peer education has been effective in condom use. Developing condom use is mainly because one of the most important interventions in HIV, HBV, and STD prevention is increasing condom use [30-33]. In spite of all attempt of health programs to extend protected sexual intercourse among high-risk individuals, many studies show that the majority of women with SRDs do not use condoms [34, 35]. Accordingly, the positive impact of $\mathrm{PE}$, as a serious program in drop-in centres, camps, and dormitories, could be used to enhance condom use in women with SRDs. Besides that, education of men should be taken into consideration because most women remarked that the reason for not using a condom is because of their partner's unwillingness; hence, male education might be accompanied by more effective and sustainable results. The aim of the interven- tion by Xiushi Yang and Guomei Xia was to reduce HIV high-risk behaviours, and this was done in two groups: one group educated by their peers and the other group given professional training, although in three-month follow up the professionally educated group had lowered their risk behaviours. But in six- and 12-month follow-ups, the peer-educated group had been using the condom and reducing their high-risk behaviours sustainably more [36]. Hence, peer education can be more successful and longer lasting.

In the current study drug and alcohol use before sexual intercourse was another outcome that was assessed. The results show that the amount of drug and alcohol use before sexual intercourse and the number of sex acts under the influence of drugs and alcohol in the intervention group significantly declined compared to the control group (Tables 2 and 3). Many studies have shown that SRDs, by disrupting the power of judgment and inhibitive behaviour, lead to increasing involvement in high-risk behaviours, especially high-risk sexual behaviours [10, 13, 15, 37-39], particularly if the substance use occurs immediately before the sexual activity [11]. As a result, improving these consequences is important because this reduction can play a great role in preventing high-risk sexual intercourse, thus preventing HIV and HBV infection [40]. In the present study, multi-drug using was in the second place of drugs use. Various studies have shown that multi-drug use relates to multiple sexual partners, trade sex for drugs and money, and other high-risk sexual behaviours [41-43]. No research was found regarding the effect of peer education on the reduction of sex under the influence of drugs and alcohol. Along with the results of the present study, the intervention results of Calsyn et al. have shown that the frequency of sex acts under the influence of drugs and alcohol was reduced in three-month follow-up, although in six-month follow-up no difference was observed between the two groups [44]. It seems that PE due to the continuity of communication of peers, has better long-term efficacy and leads to a change in behaviour. Some other studies have successfully reduced the consumption of alcohol and drugs in participants with SRDs [45, 46]. Many studies have been done in an attempt to reduce alcohol and drug use before sex acts and to reduce sexual risk behaviours. Interventions that had more sessions and in the form of a group, such as the those by Rotheram-Borus et al., Slesnick and Kang, Slesnick et al., were more effective than those that had a single, brief, and individual consulting session like that of Thompson et al. [47-52]. Reducing sexual intercourse influenced by drugs has a direct impact on increasing general health, and its relationship with high-risk sexual behaviours determine the extent of these benefits [53].

In the current study, $56 \%$ of participants in the intervention group and $62 \%$ in the control group had multiple sexual partners during the previous three months. Our data indicate that the intervention arm showed a significant decrease in the mean number of sexual partners at one- and three-month follow-ups, compared to the control group. 


\begin{tabular}{|c|c|c|c|c|c|}
\hline \multicolumn{2}{|c|}{ 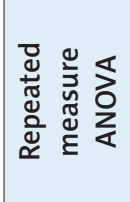 } & 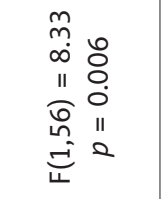 & 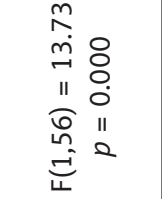 & 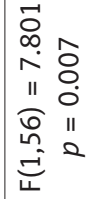 & 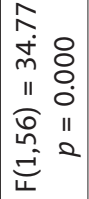 \\
\hline \multicolumn{2}{|c|}{ L } & $\begin{array}{l}m \\
\infty \\
\stackrel{+}{*}\end{array}$ & $\begin{array}{l}\text { LO } \\
\text { in }\end{array}$ & $\stackrel{\sim}{\underset{m}{m}}$ & $\begin{array}{l}n \\
\infty \\
\varphi \\
\varphi\end{array}$ \\
\hline \multicolumn{2}{|c|}{$\begin{array}{l}\frac{0}{\frac{0}{N}} \\
\frac{N}{2} \\
0\end{array}$} & ০̊ & : & $\begin{array}{l}\circ \\
\stackrel{0}{\circ} \\
\end{array}$ & $\begin{array}{l}8 \\
\vdots \\
0\end{array}$ \\
\hline \multirow[b]{2}{*}{ 列 } & 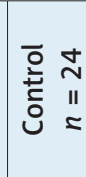 & $\begin{array}{l}\stackrel{n}{\hat{\alpha}} \\
+1 \\
+1 \\
\hat{\alpha} \\
0\end{array}$ & $\begin{array}{l}\overrightarrow{0} \\
\stackrel{i}{+} \\
+1 \\
\infty \\
\infty \\
-i\end{array}$ & $\begin{array}{l}\hat{N} \\
0 \\
+1 \\
\vec{a} \\
\dot{N}\end{array}$ & 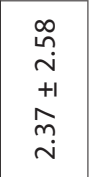 \\
\hline & 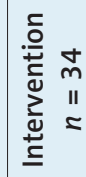 & $\begin{array}{l}\hat{\infty} \\
\stackrel{i}{i} \\
+1 \\
\sim \\
\tilde{n}\end{array}$ & $\begin{array}{l}+ \\
m \\
0 \\
+1 \\
n \\
0 \\
0 \\
0\end{array}$ & 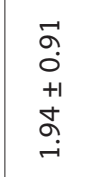 & $\begin{array}{l}\infty \\
\stackrel{\infty}{+} \\
\stackrel{+}{+1} \\
+ \\
\hat{a} \\
i\end{array}$ \\
\hline \multicolumn{2}{|c|}{ r } & $\stackrel{m}{\stackrel{m}{f}}$ & 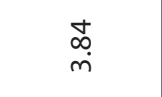 & $\stackrel{\substack{n \\
\sim}}{\stackrel{m}{*}}$ & 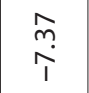 \\
\hline \multicolumn{2}{|c|}{$\begin{array}{l}\frac{0}{3} \\
\frac{5}{2} \\
x^{2}\end{array}$} & ঃ & ঃ & ঃ & ঃ \\
\hline \multirow{2}{*}{ 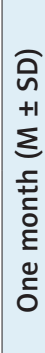 } & 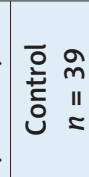 & $\begin{array}{l}\stackrel{0}{0} \\
m \\
m \\
+1 \\
0 \\
0 \\
\dot{0}\end{array}$ & $\begin{array}{l}0 \\
0 \\
-1 \\
+1 \\
0 \\
o \\
i \\
-1\end{array}$ & $\begin{array}{l}\tilde{N} \\
\dot{T} \\
+1 \\
\stackrel{+}{0} \\
\dot{m}\end{array}$ & $\begin{array}{l}\stackrel{0}{\stackrel{i}{*}} \\
+1 \\
\stackrel{+}{i}\end{array}$ \\
\hline & 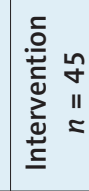 & $\begin{array}{l}\infty \\
\stackrel{1}{1} \\
i \\
+1 \\
\infty \\
m\end{array}$ & $\begin{array}{l}\tilde{\alpha} \\
\vdots \\
+1 \\
+1 \\
m \\
m \\
o\end{array}$ & $\begin{array}{l}n \\
0 \\
0 \\
+1 \\
0 \\
0 \\
\text { j }\end{array}$ & $\begin{array}{l}m \\
m \\
\rightarrow+ \\
+1 \\
o \\
\dot{n}\end{array}$ \\
\hline \multirow{2}{*}{ 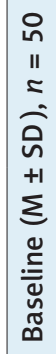 } & 일 & $\begin{array}{l}\stackrel{0}{m} \\
m \\
m \\
+1 \\
\tilde{o} \\
0 \\
0\end{array}$ & $\begin{array}{l}o \\
\stackrel{+}{+} \\
+1 \\
\stackrel{+}{-}\end{array}$ & $\begin{array}{l}\underset{J}{J} \\
\underset{i}{+1} \\
+1 \\
m \\
m \\
m\end{array}$ & $\begin{array}{l}\infty \\
\infty \\
i \\
+1 \\
\hat{\alpha} \\
\stackrel{+}{+}\end{array}$ \\
\hline & 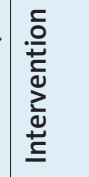 & $\begin{array}{l}-1 \\
\dot{+} \\
+1 \\
+ \\
\dot{0} \\
\dot{0}\end{array}$ & 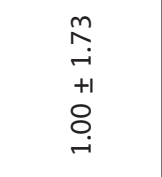 & $\begin{array}{l}\hat{b} \\
i \\
+1 \\
0 \\
\infty \\
\dot{m} \\
\end{array}$ & $\begin{array}{l}\infty \\
0 \\
\dot{m} \\
+1 \\
0 \\
\infty \\
\infty \\
-i\end{array}$ \\
\hline \multicolumn{2}{|c|}{$\frac{\sqrt{\frac{0}{2}}}{\frac{\pi}{3}}$} & 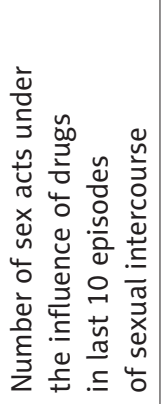 & 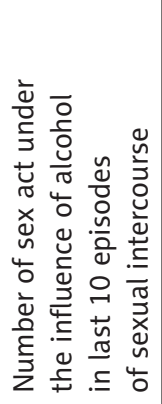 & 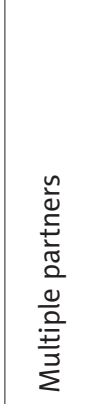 & 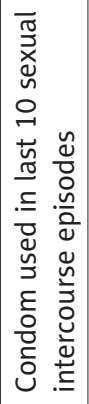 \\
\hline
\end{tabular}

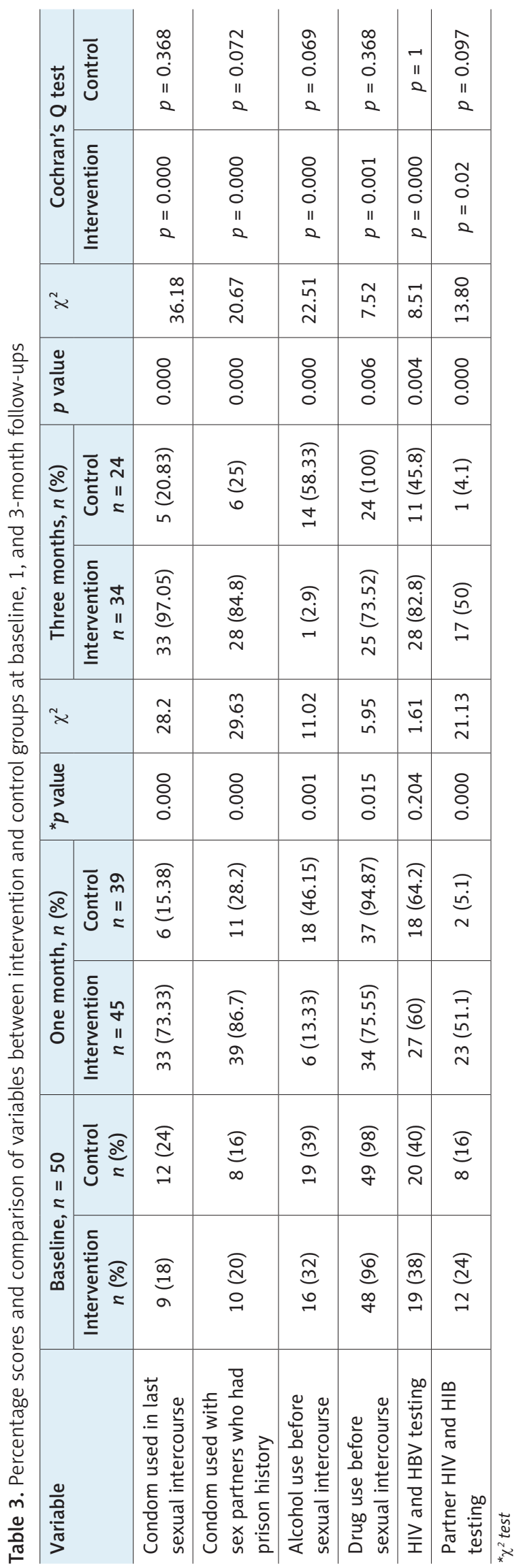


While the control group did not demonstrate any significant difference. Along with this study, a study was conducted by Surratt et al. in two groups: one group educated by their peers and the other group given professional education, in three- and six-month follow-ups the two groups showed a significant decrease in the mean number of sexual partners $(p<0.01)$ and a significant increase in HIV testing $(p<0.01)$ [21]. Reducing sexual partners is an important consequence in the prevention of HIV and HBV infection because multiple sex partners increases the risk of HIV and HBV infections [27]. This risk increases especially in persons with SRDs [10]. The results of the studies are different in relation to the impact of the intervention on the number of sexual partners. For instance, some results $[21,46,54]$ show a decrease in the number of sexual partners but in other $[28,55]$ no significant difference was observed in the number of sexual partners. Probably these differences are due to the type and focus of intervention and also the difference in the research community. Because some of the studies were on sex workers and women frequently enter sex work because of financial pressures and these financial incentives may be due to having multiple sexual partners.

Our findings indicate that the percentage of HIV and HBV testing significantly increased in both groups, and in one-month follow-up the two groups showed no significant difference, but in three-month follow-up most of the participants in the trial arm tested for HIV in the previous month and a significant increase was seen compared to control group. This increase is very important because HIV and HBV testing play a serious role in understanding epidemics and health planning. The results of Blas et al. show that most of the participants gave the reason for not testing for HIV and HBV as fear about a positive test result and lack of knowledge about testing centres [56]. Before the intervention, most of the women said that awareness of their HIV and HBV state is not helpful in preventing high-risk behaviours. Also, studies show that it is more likely that women inform their permanent sexual partners compared to casual or temporary sexual partners $[57,58]$. In a qualitative study with the aim of identifying the perceptions of drug-abusing women toward HIV status in Iran, it was shown that HIV-positive and sex working women were more likely to keep their HIV status hidden, and their reason was financial support. Overall, most women preferred to inform their sexual partners about their HIV status as the first person [59].

Several limitations of this study should be noted. As with most research of this nature, we relied on self-reported behaviour, the limitations of which are well-known. The existing evidence for the validity of self-reported health service utilisation is mixed; some studies indicate high levels of correspondence between self-report and medical record data, while others document large discrepancies [60, 61]. Recruitment was limited to drug-involved women. Another limitation is the three-month follow-up period; further research is needed to determine whether the short-term effects that we found are sustained over a longer period of time. Behavioural interventions, especially education type, need more follow-up, to obtain real results about changed risk behaviours. Another limitation was the participants' place of residence. Many of the participants were homeless and residents of shelters; as a result, we lost some of them in the follow-ups, which reduces the statistical power and generalisability of the results.

The results of the current study showed the importance of pursuing HIV and HBV intervention initiatives among SRDs. We found that peer education intervention is an acceptable and engaging method in a street-based population of SRDs, and also produced significant effects on risk behaviours for HIV and HBV infection and transmission. From a public health perspective, reducing HIV and HBV transmission in an SRD context may have a considerable impact on the prevalence of these diseases. Nevertheless, interventions for SRDs going forward should address structural level challenges, in addition to individual-level barriers. Successful approaches in the longer-term must include intervention models, but inroads must also be made to improve the viability of connections to the health service system. Peer education programs are more beneficial and easy to implement, and the government can take advantage of them for harm-reduction policies.

\section{Acknowledgements}

This research was supported by Iran University of Medical Sciences, State Welfare Organisation of Tehran, Iran. State Welfare Organisation of Rey, Tehran.

\section{Conflict of interest}

The authors declare no potential conflicts of interest with respect to the research, authorship, and/or publication of this article.

\section{References}

1. Shamsalina A, Norouzi K, Fallahi Khoshknab M, Farhoudiyan A. Recovery based on spirituality in substance abusers in Iran. Glob J Health Sci 2014; 6: 154-162.

2. Khajedaluee M, Assadi R, Dadgar Moghadam M. Health-related quality of life of young addict women in Mashhad, IR Iran. Int J High Risk Behav Addict 2013; 2: 87-91.

3. Iran DCH. The counselor secretary general of the country's Drug Control Headquarters. Drug Control Headquarters; 2014. Available from: http://www.khabaronline.ir/detail/334514/society/socialdamage (Accessed: 25.01.2016).

4. WHO. HIV/AIDS Women's Health World Health Organization; 2018. Available from: https://www.who.int/news-room/fact-sheets/ detail/hiv-aids (Accessed: 19.07.2018).

5. Weissman J, Kanamori M, Devieux JG, Trepka MJ, De La Rosa M. HIV risk reduction interventions among substance-abusing reproductive-age women: a systematic review. AIDS Educ Prev 2017; 29: 121-140.

6. Thiede H, Hagan H, Campbell JV, et al. Prevalence and correlates of indirect sharing practices among young adult injection drug users in five U.S. cities. Drug Alcohol Depend 2007; 91 Suppl 1: S39-47. 
7. Huo D, Ouellet LJ. Needle exchange and sexual risk behaviors among a cohort of injection drug users in Chicago, Illinois. Sex Transm Dis 2009; 36: 35-40.

8. Mackesy-Amiti ME, Finnegan L, Ouellet LJ, et al. Peer-education intervention to reduce injection risk behaviors benefits high-risk young injection drug users: a latent transition analysis of the CIDUS 3/DUIT study. AIDS Behav 2013; 17: 2075-2083.

9. UNIADS. UNAIDS DATA 2017: United Nations Programme on HIV/ AIDS (UNAIDS); 2017. Available from: http://www.unaids.org/en/resources/documents/2017/2017_data_book (Accessed: 20.07.2017).

10. Calsyn DA, Cousins SJ, Hatch-Maillette MA, et al. Sex under the influence of drugs or alcohol: common for men in substance abuse treatment and associated with high risk sexual behavior. Am J Addict 2010; 19: 119-127.

11. CDC. HIV Among Youth Fact Sheet; 2015: Centers for Disease Control and Prevention; 2015. Available from: http://www.cdc.gov/ hiv/group/age/youth/index.html (Accessed: 2.12.2015).

12. Merghati-Khoei ES, Rezaei Z, Shojaei-Zadeh D, et al. Sexual risk behaviors and condom use barriers in iranian men with substance use disorders. Addict Health 2017; 9: 40-47.

13. Carmona J, Slesnick N, Guo X, Letcher A. Reducing high risk behaviors among street living youth: Outcomes of an integrated prevention intervention. Child Youth Serv Rev 2014; 43 (Suppl C): 118-123.

14. Noor SW, Ross MW, Lai D, Risser JM. Use of latent class analysis approach to describe drug and sexual HIV risk patterns among injection drug users in Houston, Texas. AIDS Behav 2014; 18 Suppl 3: 276-283.

15. Paquette R, Tanton C, Burns F, et al. Illicit drug use and its association with key sexual risk behaviours and outcomes: findings from Britain's third National Survey of Sexual Attitudes and Lifestyles (Natsal-3). PLoS One 2017; 12: e0177922.

16. Deutsch C, Senderowitz J, Mahler H. Standards for peer education programmes. 2005.

17. Jain B, Krishnan S, Ramesh S, Sabarwal S, Garg V, Dhingra N. Effect of peer-led outreach activities on injecting risk behavior among male drug users in Haryana, India. Harm Reduct J 2014; 11: 3.

18. Abdi F, Simbar M. The peer education approach in adolescents - narrative review article. Iranian J Public Health 2013; 42: 1200-1206.

19. Cornish F, Campbell C. The social conditions for successful peer education: a comparison of two HIV prevention programs run by sex workers in India and South Africa. Am J Commun Psychol 2009; 44: 123-135.

20. Adeomi AA, Adeoye OA, Asekun-Olarinmoye EO, Abodunrin OL, Olugbenga-Bello AI, Sabageh AO. Evaluation of the effectiveness of peer education in improving HIV knowledge, attitude, and sexual behaviours among in-school adolescents in Osun State, Nigeria. AIDS Res Treat 2014; 2014: 131756

21. Surratt HL, O'Grady C, Kurtz SP, Levi-Minzi MA, Chen M. Outcomes of a behavioral intervention to reduce hiv risk among drug-involved female sex workers. AIDS Behav 2014; 18: 726-739.

22. Skolnik R. Essentials of global health. Jones \& Bartlett Publishers; 2008.

23. Story CR, Gorski J. Global perspectives on peer sex education for college students. International Education 2014; 42 : 6.

24. Nayebi N, Dolatian M, Hasan Pour Azghadi B, Ebadi A, Akbarzadeh Baghban A. Domestic violence and its association with domains of reproductive health in women: a systematic review. Journal of Mazandaran University of Medical Sciences 2018; 27: 205-217.

25. Tuchman E. Women and addiction: the importance of gender issues in substance abuse research. J Addict Dis 2010; 29: 127-138.

26. Azim T, Bontell I, Strathdee SA. Women, drugs and HIV. Int J Drug Policy 2015; 26 Suppl 1: S16-21.

27. Amirkhanian YA, Kelly JA, Takacs J, et al. Effects of a social network HIV/STD prevention intervention for MSM in Russia and Hungary: a randomized controlled trial. AIDS (London, England) 2015; 29: 583-593.
28. Bulduk S, Erdogan S. The effects of peer education on reduction of the HIV/sexually transmitted infection risk behaviors among Turkish university students. J Assoc Nurses AIDS Care 2012; 23: 233-243.

29. Jamshidimanesh M. Development and effectiveness evaluation skill promotion approch on the high risk sexual behaviours of women with substance related disorders: a mixed method study. Shahrod University of Medical Science, Shahrod 2015.

30. Garfein RS, Golub ET, Greenberg AE, et al. A peer-education intervention to reduce injection risk behaviors for HIV and hepatitis $\mathrm{C}$ virus infection in young injection drug users. AIDS (London, England) 2007; 21: 1923-1932.

31. Kippax S, Holt M. Diversification of risk reduction strategies and reduced threat of HIV may explain increases in condomless sex. AIDS (London, England) 2016; 30: 2898-2899.

32. Malery Khah Langeroudi Z, Rahimi movaghar A, Delbarpour Ahmadi S, Esmaeili M. Barriers of condom use among female sex workers in Tehran, a qualitative study. J Sch Public Health Instit Public Health Res 2014; 12: 23-34.

33. Paz-Bailey G, Wejnert C, Mendoza MC, Prejean J. Response to diversification of risk-reduction strategies and reduced threat of HIV may explain increases in condomless sex. AIDS (London, England) 2016; 30: 2900-2901.

34. Beltzer N, Saboni L, Sauvage C, Lydie N, Semaille C, Warszawski J. An 18-year follow-up of HIV knowledge, risk perception, and practices in young adults. AIDS (London, England) 2013; 27: 1011-1019.

35. Nobakht A, Mohraz M, Rahimzadeh M, Tehranizadeh M, BayatJozani Z, Esmaelzadeh S. The effect of cognitive-behavioural therapy on the reproductive health of women with HIV: a randomised controlled trial. HIV AIDS Rev 2017; 16: 236-243.

36. Yang X, Xia G. Effectiveness of a peer-assisted multicomponent behavioral intervention in HIV risk reduction among female entertainment workers in China. AIDS Educ Prev 2015; 27: 446-4164.

37. Feaster DJ, Parish CL, Gooden L, et al. Substance use and STI acquisition: secondary analysis from the AWARE study. Drug Alcohol Depend 2016; 169: 171-179.

38. Wirtz A, Zelaya C, Latkin C, et al. Alcohol use and associated sexual and substance use behaviors among men who have sex with men in Moscow, Russia. AIDS Behav 2016; 20: 523-536.

39. Zellner T, Trotter J, Lenoir S, et al. Color it real: a program to increase condom use and reduce substance abuse and perceived stress. Int J Environ Res Public Health 2016; 13: 51.

40. Tucker JS, D'Amico EJ, Ewing BA, Miles JNV, Pedersen ER. A group-based motivational interviewing brief intervention to reduce substance use and sexual risk behavior among homeless young adults. J Subst Abuse Treat 2017; 76 (Suppl C): 20-27.

41. Santos GM, Coffin PO, Das M, et al. Dose-response associations between number and frequency of substance use and high-risk sexual behaviors among HIV-negative substance-using men who have sex with men (SUMSM) in San Francisco. J Acquir Immune Defic Syndr 2013; 63: 540-544.

42. Tobin KE, Yang C, King K, Latkin CA, Curriero FC. Associations between drug and alcohol use patterns and sexual risk in a sample of African American men who have sex with men. AIDS Behav 2016; 20: 590-599.

43. Connor JP, Gullo MJ, White A, Kelly AB. Polysubstance use: diagnostic challenges, patterns of use and health. Curr Opin Psychiatry 2014; 27: 269-275.

44. Calsyn DA, Crits-Christoph P, Hatch-Maillette MA, et al. Reducing sex under the influence of drugs or alcohol for patients in substance abuse treatment. Addiction (Abingdon, England) 2010; 105: 100-108.

45. Monti PM, Mastroleo NR, Barnett NP, Colby SM, Kahler CW Operario D. Brief motivational intervention to reduce alcohol and HIV/sexual risk behavior in emergency department patients: a randomized controlled trial. J Consult Clin Psychol 2016; 84: 580-591. 
46. Parry CDH, Carney T, Petersen Williams P. Reducing substance use and risky sexual behaviour among drug users in Durban, South Africa: Assessing the impact of community-level risk-reduction interventions. SAHARA J 2017; 14: 110-117.

47. Rotheram-Borus MJ, Song J, Gwadz M, Lee M, Van Rossem R, Koopman C. Reductions in HIV risk among runaway youth. Prev Sci 2003; 4: 173-187.

48. Slesnick N, Kang MJ. The impact of an integrated treatment on HIV risk behavior among homeless youth: a randomized controlled trial. J Behav Med 2008; 31: 45-59.

49. Slesnick N, Prestopnik JL, Meyers RJ, Glassman M. Treatment outcome for street-living, homeless youth. Addict Behav 2007; 32: 1237-1251.

50. Thompson RG Jr., Elliott JC, Hu MC, Aivadyan C, Aharonovich E, Hasin DS. Short-term effects of a brief intervention to reduce alcohol use and sexual risk among homeless young adults: Results from a randomized controlled trial. Addict Res Theory 2017; 25: 24-31.

51. Bauer DJ, Sterba SK, Hallfors DD. Evaluating group-based interventions when control participants are ungrouped. Multivariate Behav Res 2008; 43: 210-236.

52. Peterson PL, Baer JS, Wells EA, Ginzler JA, Garrett SB. Short-term effects of a brief motivational intervention to reduce alcohol and drug risk among homeless adolescents. Psychol Addict Behav 2006; 20: 254-264.

53. Copenhaver MM, Lee IC, Margolin A. Successfully integrating an HIV risk reduction intervention into a community-based substance abuse treatment program. Am J Drug Alcohol Abuse 2007; 33: 109-120.

54. Oldenburg C, Chanda MM, Ortblad KF, et al. Effect of HIV selftesting on the number of sexual partners among female sex workers in Zambia: a randomized controlled trial. AIDS (London, England) 2018; 32: 645-652.

55. Lauby J, Zhu L, Milnamow M, et al. Get real: evaluation of a community-level HIV prevention intervention for young MSM who engage in episodic substance use. AIDS Educ Prev 2017; 29: 191-204.

56. Blas MM, Alva IE, Cabello R, Carcamo C, Kurth AE. Risk behaviors and reasons for not getting tested for HIV among men who have sex with men: an online survey in Peru. PLoS One 2011; 6: e27334.

57. Wang K, Fu H, Longfield K, Modi S, Mundy G, Firestone R. Do community-based strategies reduce HIV risk among people who inject drugs in China? A quasi-experimental study in Yunnan and Guangxi provinces. Harm Reduct J 2014; 11: 15.

58. Kumar A, Waterman I, Kumari G, Carter AO. Prevalence and correlates of HIV serostatus disclosure: a prospective study among HIV-infected postparturient women in Barbados. AIDS Patient Care STDS 2006; 20: 724-730.

59. Jamshidimanesh M, Khoie EM, Mousavi SA, Keramat A, Emamian MH. Perceptions of Iranian female drug users toward HIV testing: a qualitative content analysis. J Int Assoc Provid AIDS Care 2017; 16: 555-561.

60. Reijneveld SA, Stronks K. The validity of self-reported use of health care across socioeconomic strata: a comparison of survey and registration data. Int J Epidemiol 2001; 30: 1407-1414.

61. Sohler NL, Coleman SM, Cabral H, Naar-King S, Tobias C, Cunningham CO. Does self-report data on HIV primary care utilization agree with medical record data for socially marginalized populations in the United States? AIDS Patient Care STDS 2009; 23: 837-843. 